\title{
EVALUASI KINERJA METHYL DIETHANOL AMINE (MDEA) DALAM PENYERAPAN KANDUNGAN H2S PADA PROSES PENGOLAHAN GAS ALAM
}

\author{
Sutanto $^{1^{*}}$, Ade Heri Mulyati ${ }^{1}$, Hermanto ${ }^{1}$ \\ ${ }^{1}$ Program Studi Kimia, FMIPA, Universitas Pakuan, Bogor. \\ *e-mail: sutanto@unpak.ac.id
}

diterima: 31 Januari 2020; direvisi: 18 Februari 2020; disetujui: 28 Maret 2020

\begin{abstract}
ABSTRAK
Pengeboran gas alam mengandung uap air $\left(\mathrm{H}_{2} \mathrm{O}\right)$ dan gas kontaminan seperti $\mathrm{CO}_{2}$ dan $\mathrm{H}_{2} \mathrm{~S}$ yang harus dihilangkan karena mengurangi nilai kalori produk. Gas $\mathrm{H}_{2} \mathrm{~S}$ juga merupakan peralatan yang korosif dan mudah rusak sehingga meningkatkan biaya perawatan. Proses menghilangkan gas $\mathrm{CO}_{2}$ dan $\mathrm{H}_{2} \mathrm{~S}$ menggunakan MDEA (methyl diethanolamine). Penelitian ini bertujuan untuk menentukan konsentrasi optimal dan laju aliran absorben metil dietanolamin (MDEA) untuk menyerap $\mathrm{H}_{2} \mathrm{~S}$ dalam aliran gas tanaman I dalam Energy Equity Epic (Sengkang) Pty.Ltd. Penelitian ini dilakukan dengan laju alir penyerap campuran MDEA yang mantap (50\% amina murni dan 50\% air demineralisasi) ditetapkan pada 13 US Galon per menit yang mengalir terus menerus di lubang masuk penyerap atas, laju aliran gas asam, di bagian bawah penyerap. masuk dengan variasi dalam aliran gas yaitu 7,9,11,13,15,17 MMSCFD dan dihubungi dengan solusi amina counter-current. Gas alam murni (gas manis) dihasilkan dari outlet kolom penyerap teratas dengan kandungan $\mathrm{H}_{2} \mathrm{~S}$ di bawah $10 \mathrm{ppm}$. Hasil penelitian menunjukkan bahwa semakin besar laju aliran masuk gas, semakin besar gas asam diserap. Jumlah gas yang masuk dan keluar gas mengikuti persamaan $\mathrm{y}=0,003 \mathrm{x}-2,2537$. Kemampuan larutan amina untuk menyerap $\mathrm{H}_{2} \mathrm{~S}$ mengikuti persamaan logaritmik $y=0,167 \ln (x)+101,02$ dengan nilai $R=0,9857$, y adalah $\mathrm{H}_{2} \mathrm{~S}$ yang diserap oleh larutan amina dan $\mathrm{x}$ adalah laju $\mathrm{H}_{2} \mathrm{~S}$.
\end{abstract}

Kata Kunci: Gas Alam, H2S, kadar Amine, MDEA (methyl diethanol amine).

\section{PERFORMANCE EVALUATION OF METHYL DIETHANOL AMINE (MDEA) IN THE ABSORPTION OF H2S CONTENT IN THE NATURAL GAS PROCESSING}

\begin{abstract}
Drilling natural gas contains water vapor $\left(\mathrm{H}_{2} \mathrm{O}\right)$ and contaminant gases such as $\mathrm{CO}_{2}$ and $\mathrm{H}_{2} \mathrm{~S}$ which must be removed because it reduced the calorie value of the product. $\mathrm{H}_{2} \mathrm{~S}$ gas is also corrosive, easily damaging equipment so that it increased maintenance costs. The process of removing $\mathrm{CO}_{2}$ and $\mathrm{H}_{2} \mathrm{~S}$ gas uses MDEA (methyl diethanolamine). This study aims to determine the optimal concentration and flow rate of absorbent methyl diethanolamine (MDEA) to absorb $\mathrm{H}_{2} \mathrm{~S}$ in the plant I gas flow in Energy Equity Epic (Sengkang) Pty.Ltd. The study was carried out with a steady MDEA mix absorbent flow rate (50\% pure amine and 50\% demineralization water) fixed at 13 US Gallons per minute flowing continuously at the upper absorber inlet, sour gas flow rate, at the bottom of the absorber inlet with variations in the flow gas namely $7,9,11,13,15,17$ MMSCFD and is contacted with amine solution counter-current. Purified natural gas (sweet gas) produced from the top absorber column outlet with an $\mathrm{H}_{2} \mathrm{~S}$ content below $10 \mathrm{ppm}$. The results showed that the greater the flow rate of gas inlet, the greater the acid gas absorbed. The amount of gas entering and exiting gas follows the equation $y=0.003$ $\mathrm{x}-2.2537$. The ability of the amine solution to absorb $\mathrm{H}_{2} \mathrm{~S}$ follows the logarithmic equation $\mathrm{y}=$ $0.167 \ln (\mathrm{x})+101.02$ with a value of $\mathrm{R}=0.9857, \mathrm{y}$ is $\mathrm{H}_{2} \mathrm{~S}$ absorbed by the amine solution and $\mathrm{x}$ is the $\mathrm{H}_{2} \mathrm{~S}$ rate.
\end{abstract}

Key words: Natural Gas, CO2, H2S, MDEA (methyl diethanol amine), amine content. 


\section{PENDAHULUAN}

Gas alam seperti juga minyak bumi adalah bahan bakar fosil yang merupakan senyawa hidrokarbon $\left(\mathrm{C}_{\mathrm{nH}} \mathrm{n}+2\right)$ dan terdiri dari campuran beberapa macam gas hidrokarbon yang mudah terbakar dan nonhidrokarbon seperti $\mathrm{N} 2, \mathrm{CO} 2$ dan $\mathrm{H} 2 \mathrm{~S}$. Umumnya gas yang terbentuk sebagian besar dari metana $(\mathrm{CH} 4)$, dan dapat juga etana (C2H6) dan propana (C3H8). Kandungan gas alam didominasi oleh gas metana mencapai antara 70-90\%, $\mathrm{CO}_{2}$ 0$8 \%$ dan $\mathrm{H}_{2} \mathrm{~S}$ 0-5 \% (Mia Afsana, 2015).

Berdasarkan Direktorat Jenderal Minyak dan Gas Bumi, 2008, gas alam digolongkan sebagai berikut :

a. Sweetgas adalah gas alam atau gas bumi yang sudah bersih (sweet), yang tidak mengandung atau relatif kecil mengandung impurities dan gas-gas kontaminan seperti $\mathrm{H} 2 \mathrm{O}$ dan $\mathrm{CO} 2$.

b. Sour gas yaitu gas alam atau gas bumi yang belum mengalami proses purifikasi atau yang belum bersih, yang masih mengandung impurities dan gas-gas ikutan atau kontaminan seperti $\mathrm{H} 2 \mathrm{O}$ dan $\mathrm{CO} 2$.

c. Wet gas yaitu gas alam yang mengandung bensin alam (Natural Gasoline) dalam jumlah yang berarti.

d. Dry gas yaitu gas alam atau gas bumi yang komponen utamanya metana tidak mengandung gasoline.

Menurut Campbell, (1988), dalam proses pemurnian gas alam melalui beberapa tahapan, yaitu Proses pemisahan atau separasi, Proses Penyaringan atau filterisasi, Proses pemurnian atau purifikasi, Proses penghilangan kandungan $\mathrm{H} 2 \mathrm{O}$ atau dehidrasi

Dalam gas alam yang masih mengandung kontaminan Hidrogen sulfida $\left(\mathrm{H}_{2} \mathrm{~S}\right)$ harus dihilangkan karena akan berpengaruh terhadap kualitas gas alam maupun terhadap kuantititasnya. Dari segi kuantitasnya, kandungan Hidrogen Sulfida dalam gas alam relatif kecil terutama gas alam dari Indonesia, maka pengaruhnya terhadap kuantitas gas alam juga kecil.

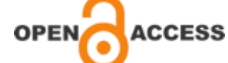

Tetapi dari segi kualitas, bila kandungan gas Hidrogen sulfida tinggi, akan menurunkan nilai kalori dari gas alam tersebut. Hal ini akan berpengaruh terhadap panas pembakaran dari produk yang dihasilkan, misalnya Liquefied Petroleum Gas (LPG), Liquefied Natural Gas (LNG), dan Compressed Natural Gas (CNG). Gas $\mathrm{H} 2 \mathrm{~S}$ juga bersifat korosif, maka akan dengan mudah merusak peralatan proses, sehingga menambah biaya pemeliharaan. Karena Gas H2S sifatnya berbau sehingga menimbulkan bau pada produk yang dihasilkan. (PI Migas 2016; Austin, 1996)

Pemilihan larutan amine yang tepat untuk digunakan secara garis besar meliputi 3 jenis: Primer, sekunder, dan tersier amine. Dari keadaan tersebut maka belakangan ini yang digunakan atau yang dikembangkan adalah Methyl Diethanol Amine (MDEA).

Proses pengolahan gas alam yang di lakukan pada Energy Equity Epic Sengkang Pty.Ltd melalui beberapa tahapan proses, yaitu metering, separator, coalescing filter, amine contactor dan TEG contactor (Alpen, 2013). Untuk memperoleh gas murni, maka dilakukan proses penghilangan kandungan gas $\mathrm{CO}_{2}$ dan $\mathrm{H} 2 \mathrm{~S}$ menggunakan bahan kimia MDEA (methyl diethanol amine) dalam sebuah bejana tertutup yang disebut contactor sehingga terjadi kontak dengan aliran gas. Larutan amine akan menyerap $\mathrm{H} 2 \mathrm{~S}$, setelah terjadi absorbsi, partikel amine menjadi lebih berat dan turun ke dasar contactor yang nantinya akan di regenerasi kembali ( Aliabad dan Mirzaei, 2009).

Efisiensi guna menekan pembiayaan pada proses produksi, dan dampak terhadap kualitas produk yang dihasilkan, dari penggunaan MDEA (methyl diethanol amine) perlu dipelajari.

Untuk dapat mengetahui unjuk kerja absorber oleh MDEA (methyl diethanol amine) pada contactor $\mathrm{V}-104$ dan penghilangan kandungan $\mathrm{H}_{2} \mathrm{~S}$ dari gasalam akan dilakukan studi kondisi operasi adsorpsi tersebut. Untuk mendapatkan datadata lapangan yang berhubungan dengan topik permasalahan ini digunakan cara 
observasi langsung dan akan di pelajari pula setiap faktor yang dapat mempengaruhi keadaan tersebut. Tujuan pada penelitian ini adalah menentukan konsentrasi dan laju alir absorben methyl diethanol amine (MDEA) optimal untuk mendapatkan hasil yang terbaik dalam menyerap $\mathrm{H} 2 \mathrm{~S}$ pada aliran gas plant I di Energy Equity Epic (Sengkang) Pty.Ltd.

\section{BAHAN DAN METODE}

Penelitian ini dilaksanakan di Energy Equity Epic (Sengkang) Pty.Ltd di Dusun Kampung Baru, Desa Poleonro Kecamatan Gilireng yang berjarak $33 \mathrm{~km}$ dari kota Sengkang Kabupaten Wajo Provinsi Sulawesi Selatan. Penelitian ini dilaksanakan pada bulan Agustus sampai dengan bulan Oktober 2018.

Alat-alat yang digunakan dalam penelitian ini antara lain, absorber column (contactor V-104), dreger tube (range 0.2 5 ppm dan 2-10 ppm), Positif Displacement pump. Capacity: 50.3 USGPM @ 1200 psig. Analog pH meter/301, Gelas Piala 100 ml, Magnetic stirer, Hydrometer, Gelas ukur $100 \mathrm{ml}, 500 \mathrm{ml}$ dan $1000 \mathrm{ml}$, Termometer, Kertas tisu, Pipet ukur, Erlenmeyer $250 \mathrm{ml}$, Gelas Beaker $250 \mathrm{ml}$, Labu ukur $500 \mathrm{ml}$, Buret $50 \mathrm{ml}$ dan $100 \mathrm{ml}$, alat pengaduk, Hydrogen Sulfide Test Kit, Gas chromatograph. Bahan yang di gunakan dalam penelitian ini antara lain, Absorber methyl diethanol amine (MDEA), Demine water,Natural gas ( gas alam) dengan kandungan $\mathrm{H} 2 \mathrm{~S} 500$ ppm, Larutan $\mathrm{H}_{2} \mathrm{SO} 40,1 \mathrm{~N}$, Indicator Methyl red, Larutan Standart pH : 7,0 atau pH : 10,0. Gas carrier Helium. Gas Kalibrasi.

\section{Metode Penelitian}

Untuk menghilangkan kandungan $\mathrm{H} 2 \mathrm{~S}$ dari gas alam digunakan proses absorpsi kimia dengan larutan methyldiethanolamine atau biasa di sebut juga dengan MDEA untuk menanggulangi kosentrasi H2S sehingga di bawah 10 ppm sesuai dengan persyaratan permintaan konsumen. Pada penelitian ini akan dilihat bagaimana pengaruh perubahan laju alir gas

OPEN ACCESS alam terhadap kemampuan konsentrasi MDEA untuk menanggulangi kandungan $\mathrm{H} 2 \mathrm{~S}$ dalam gas alam.

Data-data yang digunakan adalah data dari lapangan gas. Langkah selanjutnya adalah melakukan studi sensitivitas dengan merubah variasi gas alir di inlet absorber bagian bawah dan flow aliran amine konstan pada inlet absorber bagian atas, sehingga dapat melihat hubungan dari kedua parameter tersebut. Dari hubungan kedua parameter tersebut kemudian dapat dipilih kondisi optimal konsentrasi MDEA yang dapat digunakan untuk lapangan gas atau Plant I di Energy Equity Epic Sengkang Ltd. Variabel yang di gunakan dalam penelitian ini terdiri dari variabel tetap dan variabel bebas. Variabel tetap dalam penelitian ini adalah laju alir absorben MDEA yaitu 13 US Galon permenit. Variabel bebas dalam penelitian ini adalah laju alir gas, yaitu 7,9,12,15 dan 17 MMSCFD.

Dalam melakukan penelitian ini variabel variabel yang harus di ketahui ialah: Temperatur contactor, Tekanan gas alam pada contactor, Laju alir gas alam, Laju alir amine, Kadar amine, Komposisi aliran gas masuk dan gas keluar pada proses.tahapan yang harus dilakukan adalah: mengalirkan gas alam ke contaktor dengan variasi laju alir 7 MMSCFD selama 5 jam untuk menyakinkan bahwa aliran sudah stabil dan dapat diambil datanya.

Mengambil data dengan mengukur kandungan konsentrasi $\mathrm{H}_{2} \mathrm{~S}$ dengan menggunakan drager chip atau drager tube pada aliran masuk dan keluar contactor tiap kali ada perubahan variasi aliran gas, mengukur tekanan, temperatur pada contactor. Mengatur laju alir amine mix ( $50 \%$ pure amine dan $50 \%$ demin water) dengan kecepatan laju alir tetap yaitu 13 USG/M untuk masing masing variasi gas rate (Thermo Design Engineering, 2012).

\section{Metode Analisis}

Metode analisis antara lain, Penentuan $\mathrm{pH}$ lean amine, Pengukuran spesifik grafity, Penentuan amine strength (kadar amine) 
dalam larutan. Mengukur komposisi gas dengan Gas Chromatograph.

\section{Perhitungan}

Untuk mengetahui kadar optimal penggunaan MDEA dapat diketehui dengan melakukan perhitungan:

Laju alir total MDEA = laju alir peyerapan MDEA terhadap $\mathrm{H} 2 \mathrm{~S}$ + laju alir penyerapan MDEA terhadap $\mathrm{CO}_{2}$

\section{HASIL DAN PEMBAHASAN}

\section{Hasil Percobaan dan Prakiraan Kebutuhan MDEA}

Dengan mengalirkan gas alam ke contactor dengan variasi laju alir gas 7 , 9,11,13,15 dan 17 MMSCFD. Kebutuhan MDEA sebagai penyerap gas asam dapat diketahui dengan melakukan variasi laju alir tersebut. Berikut data rata-rata dari pengamatan pada Amine Contaktor V-104.

Tabel 1. Rata-rata Data Pengamatan Pada Amine Contaktor V-104

\begin{tabular}{|c|c|c|c|c|c|c|c|c|}
\hline Tanggal & $\begin{array}{l}\text { Lailu Alir Gas } \\
\text { (MMSCFD) }\end{array}$ & $\begin{array}{l}\text { Laju Alir } \\
\text { Amine } \\
\text { (USGPM) }\end{array}$ & $\begin{array}{l}\mathrm{H}_{2} \mathrm{~S} \text { in } \\
(\mathrm{PPM})\end{array}$ & $\begin{array}{l}\text { HiS out } \\
\text { (PPM) }\end{array}$ & $\begin{array}{l}\mathrm{CO}_{2} \text { in } \\
(\mathrm{mol})\end{array}$ & $\begin{array}{l}\mathrm{CO}_{2} \text { out } \\
\text { (mol) }\end{array}$ & $\begin{array}{c}\text { Temperatur } \\
\text { (F) }\end{array}$ & $\begin{array}{l}\text { Tekanant } \\
\text { (Psig) }\end{array}$ \\
\hline 16-Agl-18 & 7,091 & 13,03 & 389 & 0,1 & 0,3 & 0,1405 & 92,8 & 544,9 \\
\hline 22-Agl-18 & 9,023 & 13,02 & 422 & 0,4 & 0,3 & 0,1405 & 92,5 & 543,3 \\
\hline 28-Agl-18 & 11,045 & 13,04 & 426 & 0,5 & 0,3 & 0,1405 & 93 & 529,7 \\
\hline 18-Sep-18 & 13,039 & 13,03 & 422 & 0,6 & 0,3 & 0,1405 & 93 & 550,8 \\
\hline $24 \operatorname{Sep}-18$ & 15,018 & 13,06 & 427 & 0,7 & 0,3 & 0,1405 & 93 & 509,4 \\
\hline $15-0 \mathrm{kt}-18$ & 17,007 & 13.02 & 414 & 0,8 & 0,3 & 0,1405 & 93 & 508,3 \\
\hline
\end{tabular}

Dengan mengatur laju alir amine mix ( $50 \%$ pure amine dan $50 \%$ demin water) dengan kecepatan laju alir tetap yaitu 13 USG/M untuk masing masing variasi gas rate. Dan untuk mengetahui kadar optimal penggunaan MDEA sebagai pengikat gas alam dapat diketehui dengan melakukan perhitungan. Dari hasil perhitungan maka diperoleh hasil kebutuhan MDEA untuk menyerap gas asam pada gas alam tersaji dalam Tabel 2.
Tabel 2. Kebutuhan MDEA sebagai Penyerap Gas Asam

\begin{tabular}{|c|c|c|c|c|}
\hline Tanggal & $\begin{array}{c}\text { Laju Alir Gas Masuk } \\
\text { (Kg hari) }\end{array}$ & $\begin{array}{c}\text { Massa Gas Asam } \\
\text { Terabsorbsi } \\
\text { (Kg hari) }\end{array}$ & $\begin{array}{c}\text { Kebutuhan MDEA } \\
\text { (Gal/min) }\end{array}$ & $\begin{array}{c}\text { Kebutuhan MDEA } \\
\text { (Kghari) }\end{array}$ \\
\hline \hline 16-Agu-18 & 1881639,396 & $\beta 732,9844$ & 7,4381 & 42283,6900 \\
\hline 22-Agl-18 & 2394307,188 & 4828,3599 & 9,5571 & 54329,9014 \\
\hline 28-Agu-18 & 2930857,020 & 5921,7966 & 11,7123 & 66581,6508 \\
\hline 18-Sep-18 & 3459976,884 & 6976,6974 & 13,8100 & 78506,6676 \\
\hline 24-Sep-18 & 3985116,408 & 8055,1158 & 15,9291 & 90553,1603 \\
\hline 15-0kt-18 & 4512909,492 & 9062,8248 & 17,9689 & 102149,1807 \\
\hline
\end{tabular}

Hubungan antara laju alir gas masuk dengan kebutuhan MDEA ditunjukan dalam bentuk grafik yaitu pada Gambar 1 .

Gambar 1 menunjukkan bahwa semakin tinggi laju alir gas masuk maka semakin besar kebutuhan MDEA. Hal ini disebabkan semakin tinggi laju alir gas masuk maka semakin banyak gas asam yang harus diserap.

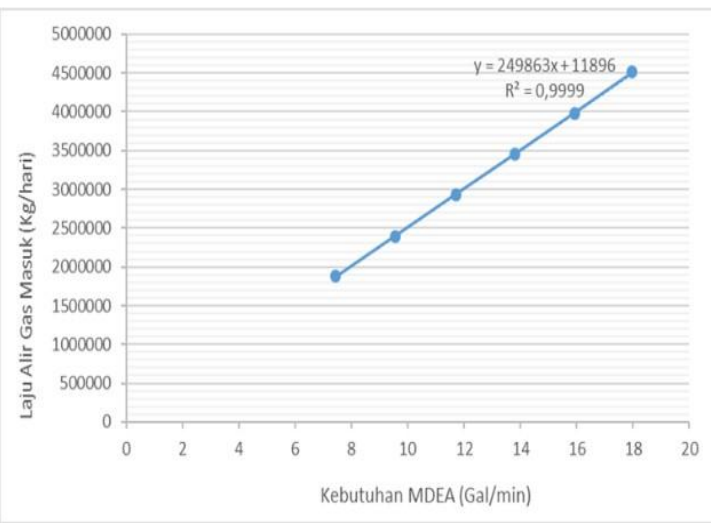

Gambar 1. Grafik laju alir penyerapan MDEA vs laju alir gas masuk pada Contaktor.

Laju alir gas masuk selalu berubah sesuai permintaan konsumen, namun laju alir MDEA yang digunakan oleh perusahaan untuk setiap laju alir gas masuk adalah konstan sekitar 13,81 gal/min (78.506,6676 kg/hari). Hal tersebut menyebabkan semakin tinggi laju alir gas masuk maka penyerapan gas asam kurang optimal dengan meggunakan laju alir MDEA yang sama. 


\section{Hubungan antara Laju Gas Masuk vs Massa Gas Asam Terabsorbs pada Contaktor}

Gas asam meliputi $\mathrm{H} 2 \mathrm{~S}$ dan $\mathrm{CO} 2$ yang berada dalam aliran gas masuk yang di serap oleh MDEA. Hubungan antara laju alir gas masuk terhadap gas asam yg terserap di contactor ditunjukkan pada Gambar 2.

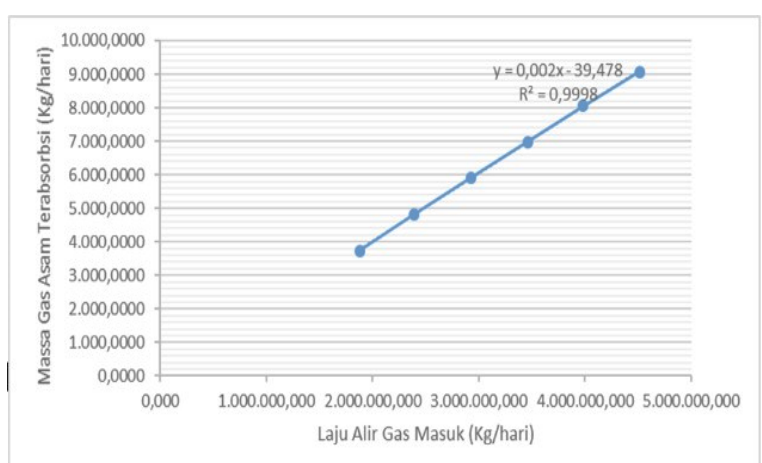

Gambar 2. Grafik massa gas asam teradsorbsi vs laju alir gas masuk

Jika laju alir gas yang rendah, maka MDEA lebih optimal dalam menyerap gas asam, namun laju alir MDEA menjadi boros. Jika dilihat dari tabel pada laju alir $1.881 .639,396 \mathrm{~kg} / \mathrm{hari}$, maka semestinya laju alir MDEA sebesar $7.4381 \mathrm{gal} / \mathrm{min}$ (42.283,6900 kg/hari) sudah cukup untuk menyerap gas asam tersebut . Maka laju alir gas yang semestinya digunakan oleh perusahaan untuk laju alir MDEA 13,81 $\mathrm{gal} / \mathrm{min}(78.506,6676 \mathrm{~kg} / \mathrm{hari})$ sebanyak $3.459 .976,884 \mathrm{~kg} / \mathrm{hari}$.

\section{Kemampuan Penyerapan Gas Asam}

Untuk menentukan kemampuan penyerapan gas asam dapat dilakukan dengan mengetahui massa gas masuk dan massa gas keluar amine contactor. Selain itu dengan mengetahui massa gas masuk dan massa gas keluar amine contactor maka dapat dihitung massa gas yang teradsorbsi pada amine contactor. Bardasarkan hasil perhitungan dapat dilihat kemampuan penyerapan MDEA terhadap gas asam sebagai berikut.
Tabel 3. Kemampuan penyerapan MDEA terhadap gas asam

\begin{tabular}{|c|c|c|c|c|c|c|c|c|}
\hline $\begin{array}{l}\text { Flowrate Gas } \\
\text { Masulk (Kg) }\end{array}$ & $\begin{array}{c}\text { Massa } \\
\text { H2S } \\
\text { Masul } \\
(\mathrm{Kg})\end{array}$ & $\begin{array}{l}\text { Masse } \\
\text { His } \\
\text { Kelluar } \\
(\mathrm{Kg})\end{array}$ & $\begin{array}{c}\text { Massa CO2 } \\
\text { Masulk } \\
(\mathrm{Kg})\end{array}$ & $\begin{array}{c}\text { Masss } \\
\mathrm{Co2} \\
\text { Keluar } \\
\left(\mathrm{Kg}_{\mathrm{g}}\right)\end{array}$ & $\begin{array}{l}\text { H2S } \\
\text { Terbabsartsi } \\
(\mathrm{Kg})\end{array}$ & $\begin{array}{c}\mathrm{CO2} \\
\text { Terbabsortsi } \\
(\mathrm{Kg})\end{array}$ & $\begin{array}{c}\text { Remampuan } \\
\text { Penyerapan } \\
\text { H2S }(\%)\end{array}$ & $\begin{array}{l}\text { Kemampuan } \\
\text { Penyerapan } \\
\cos (\%)\end{array}$ \\
\hline 1881639,396 & 731.958 & 0.188 & 5644918 & 2643,703 & 731,770 & 300121215 & 99.974 & 53.167 \\
\hline 2394307,188 & $1.010,398$ & 0,958 & 71829222 & 3364,002 & $1.009,440$ & 3818920 & 99,905 & 53,167 \\
\hline 2930857,020 & 1248,45 & 1,465 & 8792571 & 4117,854 & 1247,080 & 4674,717 & 99,883 & 53,167 \\
\hline 3459976,884 & $1.460,110$ & 2007 & 10379,931 & ${ }_{4861.268}$ & $1.558,034$ & 55118,663 & 99,858 & 53,167 \\
\hline 39855116,408 & $1.701,645$ & 2,790 & 11955,349 & 5599,089 & $1.698,855$ & 63562261 & 99,836 & 53,167 \\
\hline 4512909,492 & $1.868,345$ & 3,610 & 13338,728 & 6340,038 & 1.864734 & 7198,091 & 99,807 & 53,167 \\
\hline
\end{tabular}

Kemampuan penyerapan MDEA terhadap gas asam masih sangat optimal terlihat dari tabel diatas yang nilainya masih diatas $99 \%$.

\section{Perbandingan H2S yang masuk dengan H2S yang Keluar pada Contaktor}

Gas $\mathrm{H} 2 \mathrm{~S}$ yang berada didalam perut bumi masih memiliki kadar yang sangat tinggi sehingga dibutuhkan suatu proses pengolahan untuk mengurangi kadar gas tersebut. Perlunya penurunan kadar $\mathrm{H} 2 \mathrm{~S}$ sesuai dengan kebutuhan pasar dan standar yang digunakan. Berikut perbandingan gas $\mathrm{H} 2 \mathrm{~S}$ yang masuk kedalam contactor dan yang sudah melewati proses pengolahan pada Gambar 3.

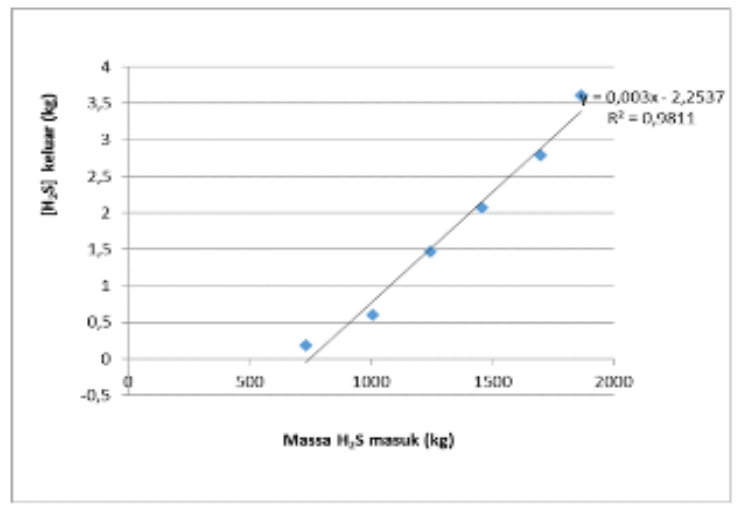

Gambar 3. Kadar $\mathrm{H} 2 \mathrm{~S}$ yang masuk dan keluar pada Contaktor

Gambar 3 menunjukkan bahwa kadar $\mathrm{H} 2 \mathrm{~S}$ yang masuk berbanding lurus dengan gas $\mathrm{H} 2 \mathrm{~S}$ yang keluar. Hal ini disebabkan

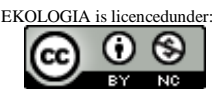


karena lajur alir gas berbeda beda. Proses penurunan kadar gas $\mathrm{H} 2 \mathrm{~S}$ telah menunjukkan hasil bahwa kadar $\mathrm{H} 2 \mathrm{~S}$ tidak melebihi 10 ppm

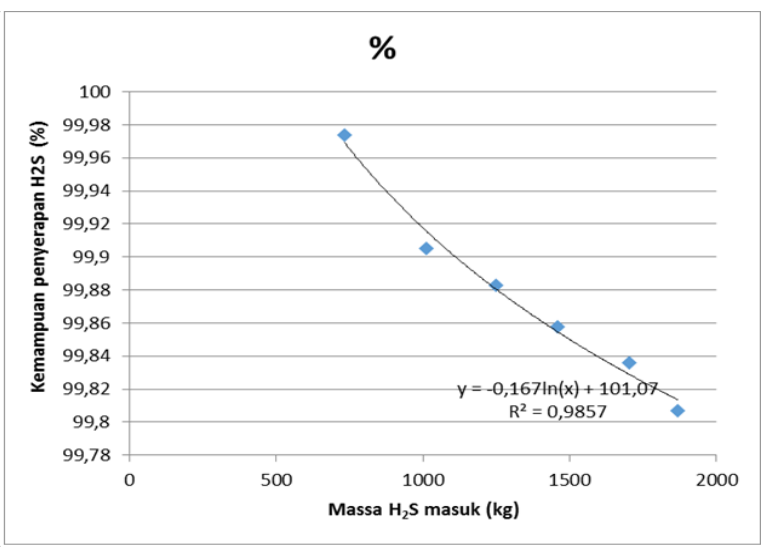

Gambar 4. Persentase Penyerapan Gas $\mathrm{H} 2 \mathrm{~S}$

Kemampuan penyerapan MDEA terhadap gas asam masih sangat optimal terlihat dari grafik pada Gambar 4. yang mempunyai nilai masih di atas 99\%, itu menandakan bahwa proses pengolahannya berjalan dengan baik.

\section{KESIMPULAN DAN SARAN Kesimpulan}

Berdasarkan penelitian dan perhitungan yang dilakukan maka dapat disimpulkan bahwa:

a. Kemampuan penjerapan MDEA terhadap gas asam yaitu 99,9\% untuk $\mathrm{H}_{2} \mathrm{~S}$ dan $53 \%$ untuk $\mathrm{CO}_{2}$.

b. Penggunaan laju alir MDEA 13,81 $\mathrm{gal} / \mathrm{min} \quad(78.506,6676 \mathrm{~kg} / \mathrm{hari})$ dapat digunakan untuk laju alir gas masuk sebesar 3.459.976,884 kg/hari untuk menghemat penggunaan MDEA.

c. Semakin besar laju alir gas masuk, gas asam yang diserap semakin besar. Besarnya gas masuk dan gas keluar mengikuti persamaan $\mathrm{y}=0,003 \mathrm{x}-$ 2,2537. Kemampuan larutan MDEA menjerap $\mathrm{H}_{2} \mathrm{~S}$ mengikuti persamaan $\operatorname{logaritma} \mathrm{y}=0,167 \ln (\mathrm{x})+101,02$ dengan nilai $\mathrm{R}=0,9857.4$, y adalah $\mathrm{H} 2 \mathrm{~S}$ yang terserap dan $x$ adalah laju $\mathrm{H}_{2} \mathrm{~S}$ yang dimasukkan.

\section{Saran}

Berdasarkan perhitungan dan pengamatan yang dilakukan, maka disarankan untuk menurunkan laju alir MDEA dengan sesuai kebutuhan saja seandainya laju alir gas masuk di bawah 3.459.976,884 kg/hari. Hal ini menghindari pemborosan penggunaan MDEA. Karena dengan laju alir MDEA yang besar akan membuat MDEA yang harus di regenerasi semakin besar dan ini berimplikasi dengan semakin beratnya kerja amine unit, kerja pompa semakin berat. Kemampuan stenght amine / menyerap $\mathrm{H} 2 \mathrm{~S}$ juga akan menurun kalau sirkulasi aliran MDEA tinggi. Penurunan laju alir MDEA di harus kan tidak akan mempengaruhi hasil pemurnian gas melebihi 10 ppm, sesuai dengan spesifikasi gas dalam kontrak jual beli gas dengan konsumen.

\section{DAFTAR PUSTAKA}

Aliabad, H. Zare. dan Mirzaei, S. (2009). Removal of $\mathrm{CO}_{2}$ and $\mathrm{H}_{2} \mathrm{~S}$ using Aqueous Alkanolamine Solutions. World Academy of Science, Engineering and Technlogy International Journal of Chemical and Molecular Engineering, Vol. 3, No. 1.

Alpen, S. (2013). PT. Energy Equity Epic Sengkang. http://www.alpensteel.com. (Diakses tanggal 28 April 2017).

Austin, George T. (1996). Industri Proses Kimia Jilid 1 Edisi 5. Jakarta: Erlangga.

Campbell, J.M. (1988). Gas Conditioning and Processing, Volume The

Equipment Modules, $6^{\text {th }}$ ed. Oklahoma: Campbell Petroleum Series.

Direktorar Jenderal Minyak dan Gas Bumi, (2008). Indonesia Petroleum Bidding Round. Ditjen Migas. Jakarta.

Mia Afsana. (2015). Pengukuran Konsentrasi Lean Amine Pada Proses Sweetening Gas Dengan Metode Titrasi di Plant II Energy Equity Epic (Sengkang) Pty.Ltd. Laporan Praktek Kerja Lapangan. Jurusan Kimia. Universitas 
Islam Indonesia. Jogjakarta.

PI, Pengetahuan Serta Informasi Tentang Migas, Energi Terbarukan dengan Pengilangan. Proses Purifikasi Gas Alam. September 22, 2016.
Thermo Design Engineering. (2012). Base Operations Manual Central Processing Plant. Energy Equity Epic (Sengkang) Pty.Ltd. 